\title{
El examen de Confundibilidad Marcaria en la Decisión 486 y su norma complementaria Decreto Legislativo 1075 \\ Sara Ynés Tello Cabello* http://dx.doi.org/10.21503/lex.v9i8.417
}

* Abogada por la Universidad Inca Garcilaso de la Vega, Doctora en Educación por la Universidad Alas Peruanas, Máster en Derecho Empresarial por la Universidad de Lima, egresada del Doctorado en Derecho por la Universidad Nacional Mayor de San Marcos, Diploma de Especialización en el 13er Curso Anual en Gestión y Dirección de Empresas por la Pontificia Universidad Católica del Perú, consultora empresarial, y docente de la Facultad de Derecho y Ciencia Política de la UAP.

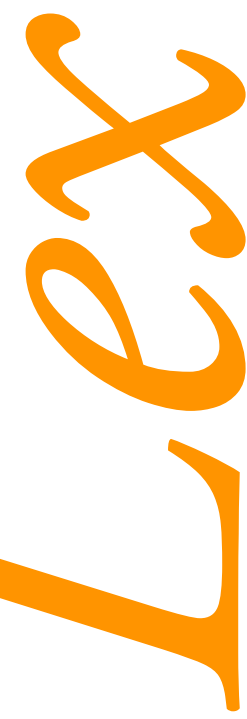




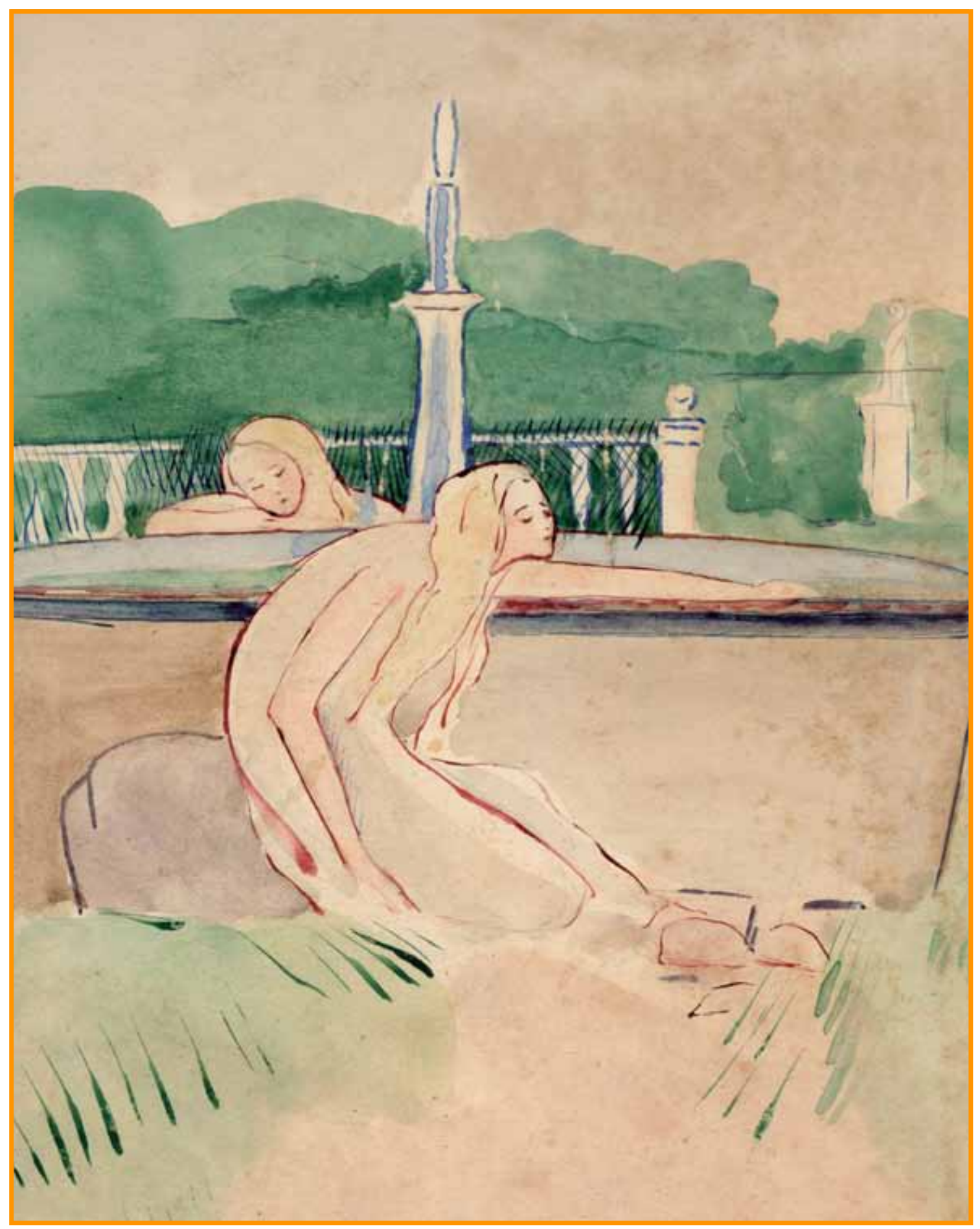




\section{Introducción}

Con la globalización y el avance de la tecnología, la propiedad industrial cumple un rol fundamental en el desarrollo de la economía de nuestro país. Si queremos que nuestro querido Perú crezca, debemos hacer empresa. Para dar protección a nuestros empresarios, necesitamos disponer de medios legales de defensa que protejan al empresario contra posibles ataques al libre ejercicio de su actividad, a sus instrumentos de actuación y a sus posibilidades comerciales. ${ }^{1}$

En el presente artículo, hemos puesto nuestro ojos en uno de los elementos constitutivos de la propiedad industrial, específicamente en la marcas de productos y de servicios, en la medida que este bien inmaterial muchas veces ha superado su valor patrimonial, es decir, a veces vale más que todos los activos que pueda tener una determinada empresa.

Siendo la marca un signo distintivo que permite distinguir productos y servicios en el mercado, la norma andina Decisión 486 y su norma complementaria Decreto Legislativo 1075 han previsto requisitos de registrabilidad de una marca, las mismas que serán sujetas a un examen de confundibilidad marcaria, con el único objetivo de evitar el posible riesgo de confusión que ellas podrían originar en el público consumidor.

\section{Definición de marca}

La marca es todo aquel signo o medio que sea apto para distinguir productos o servicios en el mercado. Esta simple definición da lugar a toda una rama del Derecho, denominada Derecho de Marca o Derecho Marcario, que se ubica metodológicamente en el Derecho Mercantil, y más propiamente en el Derecho Industrial. ${ }^{2}$

URÍA, Rodrigo. Derecho Mercantil. Marcial Pons: Madrid, 1994, p. 107.

MARTINEZ MEDRANO, Gabriel. y M. SOUCASSE, Gabriela. Derecho de Marcas. Ediciones la Roca: Buenos Aires, 2000 . 
Tanto en la legislación comunitaria como en la nacional, no ha existido siempre la misma noción de marca. Así, en la Decisión 85 se estableció que solo podía constituir marca los signos que fueran novedosos, visibles y suficientemente distintivos. Posteriormente, las decisiones 311,313 y 344 determinaron que podía registrarse como marca todo signo que fuera perceptible, suficientemente distintivo y susceptible de representación gráfica, con lo que se abrieron las puertas para el registro de sonidos y olores como marca. Ahora, con la Decisión 486 ya no cabe duda alguna. En su Artículo 134, señala que es posible registrar como marca todo signo incluido los sonidos, los olores y, bajo ciertas circunstancias, el color único. Lo anterior representa un cambio significativo que amplía grandemente las opciones comerciales y de mercadeo, pero que no han encontrado aún una solución firme en el ámbito registral, especialmente en lo referente a las marcas olfativas. ${ }^{3}$

La marca es el signo más importante y característico de las empresas en el tráfico moderno y su extraordinario valor de captación de opciones comerciales la hace insustituible como medio identificador de los resultados de la actividad empresarial. Es el instrumento más adecuado y eficaz para que el industrial y el comerciante puedan crear en su torno esa clientela adicta que define su posición como la de un cuasi-monopolio. ${ }^{4}$

Las marcas más poderosas suben su valor y ello permite al industrial crecer dentro del mercado a nivel mundial. En mayo del presente año, la consultora estratégica de marca de Millward Brown Optimor ${ }^{5}$, en su última edición, publicó un estudio acerca de las 100 marcas más valiosas del mundo. En esta edición, Apple es la marca más valiosa con un valor estimado de más de 153 millones de dólares, lo que supone un incremento en su valor de un $84 \%$ respecto al año 2010, y un 859\% desde el 2006.

\section{Funciones de las marcas}

Antes de exponer las funciones de la marca, parece oportuno aludir el importante papel que la marca desempeña en la esfera económica. La importancia de este ha sido acertadamente subrayada por el memorándum que sobre la creación de una marca comunitaria publicó en 1976 la comisión de las comunidades europeas. En este documento, se resalta de manera expresa el papel informativo que la marca debe cumplir en el seno del mercado común. A este propósito, se afirma que en la Comunidad Económica Europea el consumidor tiene que enfrentarse con un elevado de productos finales de una misma clase: productos que no se distinguen entre sí a través de características naturales o técnicas, sino tan solo mediante simples diferencias cualitativas o por medio de su aspecto externo. ${ }^{6}$

3 KRESALJA ROSELLÓ, Baldo. La propiedad Industrial, evolución y tratamiento normativo en la Región Andina y el Perú. Palestra Editores: Lima, 2004, pág. 108.

BAYLOS, Hermegildo. Tratado de Derecho Industrial. Madrid: Ed. Civitas, 1978, p. 532.

Ranking BRANDZ TOP 100 Millard Brown.

6 FERNANDEZ-NÓVOA, Carlos. Tratado sobre Derechos de Marcas. Marcial Pons: Madrid, 2004, pág.66. 
La existencia de una marca beneficia en general a todos los agentes económicos. De manera específica, este beneficio, por un lado, recae en el titular de la misma; y por otro, sobre los consumidores de los productos o servicios marcados. Analizaremos brevemente las principales funciones de la marca.

Según la función distintiva, la aplicación de una marca permite a los empresarios diferenciar los bienes y/o servicios del mismo género o especie que corresponden a sus competidores. De otro lado, la función indicadora de procedencia empresarial de los productos y servicios es, sin duda, la función primaria y fundamental de la marca: la que se apoya directamente en las reacciones de los consumidores y se basa de modo inmediato en la estructura del derecho de marcas ${ }^{7}$. Debemos precisar que esta función no necesariamente revela al consumidor el sujeto empresarial que produce determinado bien o servicio.

En tercer lugar, está la función indicadora de calidad. Según ésta, la experiencia pone de manifiesto que la contemplación de una marca enlazada con producto suscita, de ordinario, en el ánimo de consumidor la creencia de que tal producto posee ciertas características que, en algunas consideraciones, serán un tanto vagas e indeterminadas: el consumidor se limitará a pensar que un artículo de marca es igual, superior o inferior a otro artículo de marca del mismo género. A su vez, respecto de características que en otras ocasiones presentaran unos perfiles más rotundos, el consumidor atribuirá al producto o servicio de marca un determinado nivel de calidad. De uno u otro modo, es indudable que por regla general el consumidor cree que todos los productos o servicios dotados de la misma marca ostentan la misma calidad: alta y baja. ${ }^{8}$

En cuarto lugar, tenemos la función condensadora del eventual "goodwill" o "reputation". Desde la perspectiva del titular, la función más importante de la marca es, sin duda alguna, la de constituir un mecanismo en el que va condensándose progresivamente el eventual goodwill que presupone la preferencia que el público de los consumidores otorga a los productos dotados con la marca y entraña la expectativa razonable de que un producto o servicio será reiteradamente adquirido o contratado por que cuenta con el favor del público.?

Finalmente, la función publicitaria constituye uno de los puntos más discutidos al estudiar las funciones de la marca. Se trata justamente de saber si la marca cumple una función publicitaria autónoma y jurídicamente relevante. La tesis favorable al reconocimiento de la función publicitaria de la marca es mantenida en la doctrina norteamericana por Schechter, quien subraya que la marca per se constituye un medio para crear y perpetuar el goodwill;

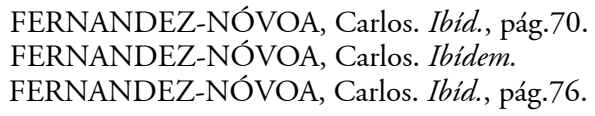


además, añade que no se describen exactamente las funciones de la marca cuando se afirma que el goodwill es la sustancia y la marca simplemente la sombra. A su juicio, la marca no es tan sólo el símbolo de goodwill, sino que es con frecuencia el mecanismo más efectivo para crear el goodwill: la marca vende efectivamente los productos.

En la doctrina española, el profesor Areán Lalín mantiene, a su vez, que la función publicitaria de la marca goza de un innegable relieve jurídico que se manifiesta en diversas instituciones del derecho de marcas; cesión y licencia de marca; marcas fuertes y de altura renombrada y sobre todo, la regulación jurídica del cambio de forma de la marca. ${ }^{10}$

La marca puede ser un instrumento para identificar bienes y servicios a través de la publicidad, permitiendo que las empresas prediquen sobre ellos sus ventajas, calidad y/o precio, logrando que los consumidores conozcan los productos como conjunto de atributos que podrían satisfacer sus necesidades o deseos y los consideren como una alternativa para su consumo.

\section{Límites de protección de una marca}

La protección del derecho de marcas no es absoluta, sino que resulta limitada por el plazo de concesión de la marca que, en este caso, a tenor del Art. 152 de la Decisión 486, es de diez años; $y$, por los principios de territorialidad, especialidad y atributivo.

El principio de territorialidad es el principio que no surge de la ley de marcas, sino del Derecho Internacional. El principio de territorialidad se ve reflejado en que la marca solo tiene valor dentro de su territorio nacional; en este caso una marca concedida en el Perú solo tiene protección en territorio peruano. Una excepción legal al principio de territorialidad estará dada por la reivindicación de prioridad unionista de una marca prevista en el artículo 4 del convenio de París.

El principio de especialidad de una marca protege a una designación, dibujo, forma, etc. Pero no para todos los productos o servicios posibles, sino solamente para los productos para los cuales se ha solicitado. Esta limitación se llama "principio de especialidad" y mantiene relación con la solicitud del industrial, debiendo indicar, de manera clara y precisa, los productos o servicios que intente proteger.

De conformidad a lo prescrito en el Art. 151 de la Decisión 486, para clasificar los productos o los servicios a los cuales se aplican a las marcas, se deberá utilizar la clasificación internacional de productos y servicios para el registro de las marcas, establecida por el arreglo

$10 \quad$ FERNANDEZ-NÓVOA, Carlos. Ibíd., pág.78. 
Niza del 15 de Junio de 1957. Para poder mantener la clasificación de NIZA al día, se revisa continuamente cada cinco años y se publican nuevas ediciones. La actual edición es la novena, la misma que se encuentra vigente desde el 1 de enero del 2007.

Finalmente, el principio atributivo, con la excepción marca notoria y renombrada, establece el requisito de registro de una marca para obtener su propiedad. La dirección de signos distintivos debe tener en cuenta los aspectos registrales, dando preeminencia a la primera marca solicitada, siendo la única excepción la marca notoria y renombrada iguales o similares a la solicitada.

\section{Requisitos para el registro de una marca}

Los requisitos esenciales de registro bajo el imperio de la Decisión 486, según opinión del Tribunal de Justicia de la Comunidad Andina, son (1) la susceptibilidad de representación gráfica y (2) la distintividad, siendo el requisito de perceptibilidad, a criterio del órgano jurisdiccional andino, un elemento presupuesto por la distintividad. Todo ello al amparo de lo establecido por el Art. 134 de la Decisión 486 de la Comisión de la Comunidad Andina y por la jurisprudencia del Tribunal Andino. ${ }^{11}$ A continuación, se presenta un caso del pronunciamiento del Tribunal sobre el concepto de marca.

Proceso 36-IP-2007 (GOAC 1515, publicado el 15 de Julio del 2007): la marca y los requisitos para su registro.

El Artículo 134 de la Decisión 486 al referirse a la marca dice: (...) constituirá marca cualquier signo que sea apto para distinguir productos o servicios en el mercado. Podrán registrarse como marca los signos susceptibles de representación gráfica. La naturaleza del producto o servicio al cual se ha de aplicar una marca en ningún caso será obstáculo para su registro (...) Este artículo tiene un contenido, da un concepto de marca, indica los requisitos que debe reunir un signo para ser registrado como marca y hace una enumeración ejemplificativa de los signos registrables.

Con base al concepto del artículo 134 de la Decisión 486, se define a la marca como un bien inmaterial constituido por un signo conformado por palabras o combinaciones de palabras, imágenes, figuras, símbolos, gráficos, logotipos, monogramas, retratos, etiquetas, emblemas, escudos, sonidos, olores, formas de los productos, sus envases o envolturas y otros elementos de soporte, individual

11 CHAVEZ PICASSO, Jorge. "El régimen común de Derecho Marcario y su interpretación por el Tribunal de Justicia de la Comunidad Andina”, en: Revista de la Competencia y la Propiedad Intelectual No 7, pp. 10-12. 
o conjuntamente estructurados que, susceptibles de representación gráfica, sirvan para distinguir en el mercado productos o servicios, a fin de que el consumidor o usuario medio los identifique, valore, diferencie, seleccione y adquiera sin riesgo de confusión o error acerca del origen o la calidad del producto o servicio. Este articulo hace una enumeración enunciativa de los signos que pueden constituir marca, por lo que el Tribunal dice que esta enumeración cubre los signos denominativos, gráficos y mixtos, pero también los tridimensionales, así como los sonoros y olfativos, lo que revela el propósito de extender el alcance de la noción de marca (Proceso 92-IP-2004, publicado en la G.O.A.C. Nro. 1121 del 28 de setiembre del 2004, marca: Universidad Virtual).

El requisito de perceptibilidad que estaba expresamente establecido en la decisión 344, se encuentra implícitamente contenido en esta definición toda vez que un signo para que pueda ser captado y apreciado es necesario que pase a ser una impresión material identificable a fin de que, al ser aprehendido por medios sensoriales y asimilado por la inteligencia, penetre en la mente de los consumidores o los usuarios. Sobre la perceptibilidad, José Manuel Otero Lastre dice “(..) Es un acierto del Articulo 134 no exigir expresamente el requisito de la perceptibilidad; porque ya está implícito en el propio concepto de la marca como bien inmaterial en el principal de sus requisitos que es la aptitud distintiva" (Otero Lastres José Manuel, "Régimen de Marcas en la Decisión 486 del Acuerdo de Cartagena (sic). Revista Jurídica del Perú, Junio 2001, p. 132).

La susceptibilidad de representación gráfica es la aptitud que tiene un signo a ser descrito o reproducido en palabras, imágenes, fórmulas u otros soportes, es decir en algo perceptible para ser captado por el público consumidor. Sobre el tema Marco Matías Alemán sostiene: La representación gráfica del signo es una descripción que permite formarse la idea del signo objeto de la marca, valiéndose para ello de palabras, figuras o signos, o cualquier otro mecanismo idóneo, siempre que tengan la facultad expresiva de los anteriormente señalados. (Alemán Marco Matías, "Normatividad subregional sobre Marcas de productos y servicios" Top Management, Bogotá, p. 77).

La distintividad es la capacidad que tiene un signo para individualizar, identificar y diferenciar en el mercado los productos y servicios, haciendo posible que el consumidor o usuario los seleccione. Es considerada como las características esenciales que debe reunir todo signo para ser registrada como marca y constituye el presupuesto indispensable para que ésta cumpla su función principal de 
identificar e indicar el origen empresarial y, en su caso incluso, la calidad del producto o servicio, sin riesgo de confusión o asociación.

En cuanto al requisito de distintividad, si bien este articulo con relación a lo que disponía el artículo 81 de la Decisión 344 no hace expresa mención a la "suficiente" distintividad, sin embargo para efecto del registro del signo, de conformidad con el literal a) del artículo 135 de la decisión $486^{\circ}$ se exige que el signo deberá ser apto para identificar y distinguir en el mercado los productos o servicios producidos o comercializados por una persona de otros idénticos o similares, con el objeto que el consumidor o usuario los valore, diferencie o seleccione, sin riesgo de confusión o de asociación en torno a su origen empresarial o a su calidad; esta exigencia se expresa también a través de la prohibición contemplada en el Art. 135, literal b, de la Decisión en referencia, según la cual no podrán registrarse como marcas los signos que carezcan de distintividad (Proceso 205IP-2005, Publicado en la G.O.A.C. N ${ }^{\circ} 1333$ del 25 de Abril del 2006, caso: Forma de una bota y sus suelas).

Se reconoce tanto una capacidad distintiva "intrínseca" como una capacidad distintiva "extrínseca" la primera se refiere a la aptitud individualizadora del signo, mientras que la segunda se refiere a su no confundibilidad con otros signos.

La marca salvaguarda tanto el interés de su titular al conferirle un derecho exclusivo sobe el signo distintivo como el interés general de los consumidores o usuarios, garantizándole el origen y la calidad de los productos o servicios, evitando el riesgo de confusión o de asociación, tomando así transparente el mercado.

En consecuencia, el Juez Consultante debe analizar en el presente caso si el signo GENPHARM cumple con los requisitos del artículo 134 de la Decisión 486 de la Comisión de la Comunidad Andina, y si no se encuentra dentro de las causales de irregistrabilidad previstas en los artículos 135 y 136 de la referida Decisión.

\section{Prohibiciones absolutas y relativas}

Al igual que la Decisión 344, la norma andina Decisión 486 ha agrupado las prohibiciones en dos categorías diferentes: Las prohibiciones absolutas y las prohibiciones relativas. Brevemente, analizaremos las siguientes cada una de las prohibiciones:

\subsection{Prohibiciones absolutas}

Previstas en el Artículo 135, esta prohibición es considerada la más importante en la medida que en su aplicación se encuentra mayores problemas. Las prohibiciones absolutas son 
aquellas que están relacionadas al signo solicitado no cumplan con las características para configurar marca. Debemos precisar que el registro de una marca, contraviniendo las prohibiciones contempladas en el Art. 135, da lugar a un supuesto de nulidad absoluta, de conformidad a lo establecido en el primer párrafo del Artículo $172^{120}$ de la Decisión $486^{\circ}$, la misma que puede ser solicitada en cualquier momento, y no tiene fecha de prescripción.

La norma ha previsto que no podrán ser registrados como marca los signos que: ${ }^{13}$

a) no puedan constituir una marca.

b) carezcan de distintividad.

c) consistan exclusivamente en formas usuales de los productos o de sus envases, o en formas o características impuestas por la naturaleza o la función de dicho producto o del servicio de que se trate.

d) consistan exclusivamente en formas u otros elementos que den una ventaja funcional o técnica al producto o al servicio al cual se aplican.

e) consistan exclusivamente en un signo o indicación que pueda servir en el comercio para describir la calidad, la cantidad, el destino, el valor, la procedencia geográfica, la época de producción u otros datos, características o informaciones de los productos o de los servicios para los cuales ha de usarse dicho signo o indicación, incluidas las expresiones laudatorias referidas a esos productos o servicios.

f) consistan exclusivamente en un signo o indicación que sea el nombre genérico o técnico del producto o servicio de que se trate.

g) consistan exclusivamente o se hubieran convertido en una designación común o usual del producto o servicio de que se trate en el lenguaje corriente o en la usanza del país.

12 Artículo 172.- La autoridad nacional competente decretará de oficio o a solicitud de cualquier persona y en cualquier momento, la nulidad absoluta de un registro de marca cuando se hubiese concedido en contravención con lo dispuesto en los artículos 134 primer párrafo y 135.

La autoridad nacional competente decretará de oficio o a solicitud de cualquier persona, la nulidad relativa de un registro de marca cuando se hubiese concedido en contravención de lo dispuesto en el artículo 136 o cuando éste se hubiera efectuado de mala fe. Esta acción prescribirá a los cinco años contados desde la fecha de concesión del registro impugnado. Las acciones precedentes no afectarán las que pudieran corresponder por daños y perjuicios conforme a la legislación interna.

No podrá declararse la nulidad del registro de una marca por causales que hubiesen dejado de ser aplicables al tiempo de resolverse la nulidad.

Cuando una causal de nulidad sólo se aplicara a uno o a algunos de los productos o servicios para los cuales la marca fue registrada, se declarará la nulidad únicamente para esos productos o servicios, y se eliminarán del registro de la marca.

13 Artículo 135 de la Decisión 486. 
h) consistan en un color aisladamente considerado, sin que se encuentre delimitado por una forma específica.

i) puedan engañar a los medios comerciales o al público, en particular sobre la procedencia geográfica, la naturaleza, el modo de fabricación, las características, cualidades o aptitud para el empleo de los productos o servicios de que se trate.

j) reproduzcan, imiten o contengan una denominación de origen protegida para los mismos productos o para productos diferentes, cuando su uso pudiera causar un riesgo de confusión o de asociación con la denominación; o implicase un aprovechamiento injusto de su notoriedad.

k) contengan una denominación de origen protegida para vinos y bebidas espirituosas.

1) consistan en una indicación geográfica nacional o extranjera susceptible de inducir a confusión respecto a los productos o servicios a los cuales se aplique.

m) reproduzcan o imiten, sin permiso de las autoridades competentes, bien sea como marcas, bien como elementos de las referidas marcas, los escudos de armas, banderas, emblemas, signos y punzones oficiales de control y de garantía de los Estados y toda imitación desde el punto de vista heráldico, así como los escudos de armas, banderas y otros emblemas, siglas o denominaciones de cualquier organización internacional.

n) Reproduzcan o imiten signos de conformidad con normas técnicas, a menos que su registro sea solicitado por el organismo nacional competente en normas y calidades en los Países Miembros;

o) reproduzcan, imiten o incluyan la denominación de una variedad vegetal protegida en un país Miembro o en el extranjero, si el signo se destinara a productos o servicios relativos a esa variedad o su uso fuere susceptible de causar confusión o asociación con la variedad.

p) sean contrarios a la ley, a la moral, al orden público o a las buenas costumbres; no obstante lo previsto en los literales b), e), f), g) y h), un signo podrá ser registrado como marca si quien solicita el registro o su causante lo hubiese estado usando constantemente en el País Miembro y, por efecto de tal uso, el signo ha adquirido aptitud distintiva respecto de los productos o servicios a los cuales se aplica.

\subsection{Prohibiciones relativas}

Previstas en el artículo 136 de la norma andina Decisión $486^{\circ}$, las prohibiciones relativas son aquellas que se basan en los derechos anteriores a terceras personas, quienes de alguna 
manera podrían verse afectados por el registro de un determinado signo. Esta prohibición se encuentra estrechamente ligada al recurso de oposición que puede interponer cualquier titular de una marca que se encuentre afectado. La concesión de una marca contraviniendo lo dispuesto en el Art. 136, o cuando este se hubiere efectuado de mala fe, da lugar a un supuesto de nulidad relativa para cuya exigencia se concede una acción que prescribe a los 5 años desde la fecha de concesión del registro impugnado, previsto en el articulo 172 (segundos párrafo). La Norma Andina ha previsto que no podrán registrarse como marca aquellos signos cuyo uso en el comercio afectara indebidamente un derecho de terceros, en particular cuando: ${ }^{14}$

a) sean idénticos o se asemejen, a una marca anteriormente solicitada para registro o registrada por un tercero, para los mismos productos o servicios, o para productos o servicios respecto de los cuales el uso de la marca pueda causar un riesgo de confusión o de asociación.

b) sean idénticos o se asemejen a un nombre comercial protegido, o, de ser el caso, a un rótulo o enseña, siempre que dadas las circunstancias, su uso pudiera originar un riesgo de confusión o de asociación;

c) sean idénticos o se asemejen a un lema comercial solicitado o registrado, siempre que dadas las circunstancias, su uso pudiera originar un riesgo de confusión o de asociación.

d) sean idénticos o se asemejen a un signo distintivo de un tercero, siempre que dadas las circunstancias su uso pudiera originar un riesgo de confusión o de asociación, cuando el solicitante sea o haya sido un representante, un distribuidor o una persona expresamente autorizada por el titular del signo protegido en el País Miembro o en el extranjero.

e) consistan en un signo que afecte la identidad o prestigio de personas jurídicas con o sin fines de lucro, o personas naturales, en especial, tratándose del nombre, apellido, firma, título, hipocorístico, seudónimo, imagen, retrato o caricatura de una persona distinta del solicitante o identificada por el sector pertinente del público como una persona distinta del solicitante, salvo que se acredite el consentimiento de esa persona o, si hubiese fallecido, el de quienes fueran declarados sus herederos.

f) consistan en un signo que infrinja el derecho de propiedad industrial o el derecho de autor de un tercero, salvo que medie el consentimiento de éste.

g) consistan en el nombre de las comunidades indígenas, afroamericanas o locales, o las denominaciones, las palabras, letras, caracteres o signos utilizados para distinguir sus productos, servicios o la forma de procesarlos, o que constituyan la expresión de su

14 Artículo 136 de la Decisión 486 
cultura o práctica, salvo que la solicitud sea presentada por la propia comunidad o con su consentimiento expreso.

h) constituyan una reproducción, imitación, traducción, transliteración o transcripción, total o parcial, de un signo distintivo notoriamente conocido cuyo titular sea un tercero, cualesquiera que sean los productos o servicios a los que se aplique el signo, cuando su uso fuese susceptible de causar un riesgo de confusión o de asociación con ese tercero o con sus productos o servicios; un aprovechamiento injusto del prestigio del signo; o la dilución de su fuerza distintiva o de su valor comercial o publicitario.

Una de las novedades de la decisión 486 es haber incorporado en su Artículo 137, las prohibiciones por competencia desleal que otorga la facultad, en este caso a la Dirección de Signos Distintivos, la posibilidad de rechazar el registro de una marca cuando tengan indicios razonables de que se ha solicitado para perpetrar, facilitar o consolidar un acto de competencia desleal.

\section{La confusión marcaria}

El riesgo de confusión es una de las figuras centrales del Derecho de la Competencia Desleal y del Derecho de Marca. En efecto, al surgir en el siglo XIX el Derecho Europeo de la Competencia Desleal, el protagonismo de esta incipiente rama jurídica es asumido por la represión de los actos de confusión. En lo que concierne al ordenamiento español, debe recordarse que los actos de confusión constituyen una de las modalidades de competencia ilícita que ya contemplaba expresamente la ley de propiedad industrial del 16 de mayo de $1902 .{ }^{15}$

Jorge Otamendi ${ }^{16}$ establece que no deben existir marcas confundibles pertenecientes a distintos titulares, porque ello perjudicaría tanto al titular de la marca que ve afectado su prestigio y mermada su clientela, como al público consumidor que compra equivocadamente.

El tratadista Núñez Del Prado ${ }^{17}$ refiere que en cuanto a la confundibilidad de las marcas idénticas o semejantes ya no se habla de que éstas sean inconfundibles, sino que deben ser "claramente distinguibles", es decir, que se acentúan la necesidad de la diferenciación de las marcas. Se dice que hay confusión cuando cotejando una marca después de la otra dejan el mismo recuerdo, la misma impresión aun cuando en los detalles existe diferencias.

FERNANDEZ-NÓVOA, Ibid., pág.273.

16 OTAMENDI, Jorge. Derecho de Marcas. Abeledo Perrot: Buenos Aires, 1995.

17 NUNEZ DEL PRADO, Oscar Holguín. Tratado de Derecho de Propiedad Industrial. Marcas de Productos y servicios (Volumen Segundo). Lima, 1997, p. 177. 


\section{Tipos de confusión marcaria}

Según Otamendi ${ }^{18}$, existen varias clases y formas confusión. En primer lugar, está la confusión directa. Esta hace que el comprador adquiera un producto determinado convencido de que está comprando otro. Es la forma clásica y más común de la confusión.

Por su parte, la confusión indirecta también engaña al consumidor, aunque en forma diferente. Se da cuando el comprador cree que el producto que desea tiene un origen, un fabricante determinado, o que ese producto pertenece a una línea de productos de un fabricante distinto de quien realmente los fabricó.

En tercer lugar, la confusión visual es la confusión causada por la identidad o similitud de los signos, sean estas palabras, frases, dibujos, etiquetas o cualquier otro por su simple observación. La jurisprudencia ha llamado a esta "la confusión gráfica", pero parece más adecuada llamarla visual, para así incluir todo aquel signo que pueda ser visto, y no tan sólo impreso. Esta calificación obedece a la manera en que se percibe la marca y no como se representa, manifiesta o expresa el signo. La confusión visual puede ser provocada por semejanzas ortográficas o gráficas, por la similitud de dibujos o de envases y de combinaciones de colores, más allá de que puedan concurrir también la confusión ideológica y la auditiva.

- La similitud ortográfica es la más habitual en los casos de confusión. Se da por la coincidencia de letras en los conjuntos en pugna. Influyen para ello, desde luego, la misma secuencia de vocales, la misma longitud y cantidad de silabas o radicales o terminaciones comunes. Ejemplo: PASA y V.A.S.A.

- La similitud gráfica existía toda vez que los dibujos de las marcas, inclusive los tipos de letras que e usen en marcas denominativas, tengan trazos parecidos o iguales. Ello aún cuando las letras o los objetos que los dibujos que representan sean diferentes. Existirá confusión derivada de la similitud gráfica cuando las etiquetas sean iguales o parecidas, sea por la similitud de la combinación de colores utilizada, sea por la disposición similar de elementos dentro de la misma o por la utilización de dibujos parecidos. La similitud gráfica es común encontrarla en las combinaciones de colores, no sólo en etiquetas, sino también en los envases.

- La similitud de forma puede darse con relación a los envases. Podrá decir que la confundibilidad entre envases es a veces difícil de determinar atento a que por la función que cumplen, necesariamente tendrán formas parecidas, por ello se les ha considerado signos marcariamente débiles, de un valor secundario exigiéndose de los nuevos registros de este tipo una novedad relativa.

${ }^{18}$ OTAMENDI, Jorge. Ibidem. 
En cuarto lugar, tenemos la confusión auditiva. Esta confusión se da cuando la pronunciación de las palabras tiene una fonética similar. Esta pronunciación puede ser correcta o deformada, lo que importa es cuál es la pronunciación que una parte considerable del publico efectúa de las palabras en cuestión. Puede ocurrir que a una palabra determinada de un idioma extranjero se le atribuyan dos pronunciaciones, la que le daría quien sabe el idioma y la que le daría el que no lo sabe.

Finalmente, tenemos la confusión ideológica expresada en las siguientes manifestaciones:

- La similitud conceptual de palabras es la que se deriva del mismo o parecido contenido conceptual de la marca. Es la representación o evocación a una misma cosa, característica o idea la que impide al consumidor distinguir una de otra.

- La similitud conceptual de dibujos ocurre cuando las marcas estén formadas por dibujos que representan una misma cosa.

- La similitud conceptual entre una palabra y un dibujo es la que existe entre una palabra y el dibujo que representa esa palabra.

- En el caso de palabras con significados contrapuestos, Refiere Otamendi, que hace unos años tratándose de las marcas DESOBESINA y OBESIN, se afirmó que "No es posible confundir ideológicamente una cosa con su contraria, si el examen conceptual sugiere contenidos contrapuestos aunque tengan un elemento de referencia común".

- En el caso de inclusión en la marca del nombre del producto a distinguir, ha habido casos en los que la marca solicitada estaba formada por el nombre del producto a distinguir y una palabra o partícula idéntica o parecida a la que formaba una marca anterior. En estos se declaró la confundibilidad de las marcas puesto que ella surgirá en el momento en que el titular de la marca anterior usará junto con ella, como era lógico el nombre del producto a distinguir.

- Entre una palabra en idioma extranjero y su traducción, ¿puede confundirse una marca formada por una palabra en otro idioma? No hay una respuesta única para todos los casos. Como principio general los idiomas extranjeros no se reputan conocidos por el público consumidor $\mathrm{y}$, por tanto, las palabras que los forman no tienen ningún significado para éste, son de fantasía. Sin embargo hay ciertos idiomas que son más conocidos que otros, como ser el italiano, el inglés y el francés, y cantidades no despreciables de personas los hablan o entienden. Ello no solo por la educación posescolar que puedan tener, sino también porque en escuelas públicas y privadas se enseñan idiomas y por los vínculos familiares extranjera bastante cercana. 


\section{El examen de Confundibilidad Marcaria}

La Dirección de Signos Distintivos es la encargada de realizar el examen de confundibilidad marcaria, cuando existan dos signos que presentan ciertos elementos semejantes o similares en sus respectivas configuraciones a fin de evitar un posible error al público consumidor respecto a la identidad de los productos o servicios que los signos en conflicto identifican y, en algunos casos, en cuanto al origen empresarial de los mismos.

El examen de confundibilidad marcaria se debe realizar cuando un tercero haya presentado un recurso de oposición a la solicitud del registro, pero ello nada impide que la Dirección de signos Distintivos, muy a pesar que no se presenta ninguna oposición realice de oficio el examen de confundibilidad.

Jorge Chávez Picasso ${ }^{19}$, en su recopilación de la más relevante jurisprudencia del Derecho Marcario del Tribunal Andino de justicia, en el ámbito de la interpretación pre judiciales con respecto a la Decisión 486 de la Comunidad Andina, ha expuesto la siguiente resolución:

proceso 42-IP-2007 (GOAC 1518, publicada el 12 de Julio del 2007); Procedimiento para el examen de registrabilidad y debida motivación de las resoluciones:

el Articulo 146 de la Decisión 486 plantea que dentro de los treinta días hábiles siguientes a la publicación, cualquier persona que tenga legítimo interés podrá presentar oposición a la concesión de las marcas solicitada. La persona que tiene legitimo interés lo acreditará ante la Oficina Nacional competente, que es la encarga de calificar tal condición.

La Oficina Nacional Competente deberá recibir y resolver las oposiciones presentadas y otorgará, por una sola vez, un plazo adicional de treinta días para presentar las pruebas que sustenten la oposición.

En consecuencia el derecho comunitario, en el presente caso la Decisión 486, establece dentro de su régimen de Propiedad Industrial quiénes son los interesados legítimos y quiénes, en consecuencia, pueden formular "oposiciones a las solicitudes de registro que se publiquen, conforme al procedimiento determinado en el Art. 146 y 150 de la Decisión en referencia.

19 CHAVEZ PICASSO, Jorge. "El régimen común de Derecho Marcario y su interpretación por el Tribunal de Justicia de la Comunidad Andina”, en: Revista de la Competencia y la Propiedad Intelectual, No 7 p. 46-47. 
El artículo 148 de la Decisión 486 dispone que en el caso en que se hayan presentado oposiciones la Oficina Nacional Competente notificará el hecho al solicitante para que, dentro de los 30 días siguientes, haga valer sus argumentaciones y, si lo considera necesario, presenta pruebas. La Oficina Nacional Competente, a solicitud de parte, otorgará 30 días de plazo adicional para presentar pruebas que sustenten la contestación.

Por otro lado, el artículo 150 de la Decisión 486 determina que vencido el plazo establecido en el Art. 148, o si no se hubiere presentado oposiciones, la oficina nacional competente procederá a realizar el examen de registrabilidad. En caso (sic) se hubiesen presentado oposiciones, la oficina nacional competente se pronunciará sobre éstas y sobre la concesión o denegatoria del régimen de la marca mediante resolución.

Por consiguiente, a la Oficina Nacional Competente, le corresponde realizar el examen de registrabilidad, el que es obligatorio y debe llevarse a cabo aun en el caso de que no hubiesen sido presentados oposiciones; en consecuencia, la Autoridad Competente en ningún caso queda eximida de realizar el examen de fondo para conceder o negar el registro. En el caso de que sean presentadas oposiciones, la Oficina Nacional Competente se pronunciará acerca de ellas así como acerca de la concesión de la denegación del registro solicitado.

$\mathrm{Al}$ respecto este Tribunal ha manifestado:

La existencia de oposiciones compromete más aún al funcionario respecto de la realización del examen de fondo, pero la inexistencia de las mismas no lo libera de la obligación de practicarlo; esto porque el objetivo de la norma es el de que dicho examen se convierta en etapa obligatoria dentro del proceso de concesión o de denegación de los registros marcarios (Proceso 16-IP-2003, publicado en la GOAC 916 del 2 de abril del 2003. Marca Construir y diseño. Tribunal de Justicia de la Comunidad Andina).

\section{Criterios aplicables por el Indecopi a efectos de establecer si dos signos son semejantes y capaces de inducir a confusión y error al consumidor}

El D. Legislativo $\mathrm{N}^{\circ} 1075$ del 28 de Junio del 2008 establece los criterios aplicables a efectos de establecer si son signos semejantes y capaces de inducir a la confusión al consumidor; para ello: 


\subsection{Determinación de Semejanza ${ }^{20}$}

A efectos de establecer si dos signos son semejantes y capaces de inducir a confusión y error al consumidor, la dirección competente tendrá en cuenta principalmente los siguientes criterios:

a) la apreciación sucesiva de los signos considerando su aspecto de conjunto, y con mayor énfasis en las semejanzas que en las diferencias;

b) el grado de percepción del consumidor medio;

c) la naturaleza de los productos o servicios y su forma de comercialización o prestación, respectivamente;

d) el carácter arbitrario o de fantasía del signo, su uso, publicidad y reputación en el mercado;

e) si el signo es parte de una familia de marcas.

\subsection{Signos Denominativos ${ }^{21}$}

Tratándose de signos denominativos, en adición a los criterios señalados en el Artículo 45 del D. Leg. $1075^{\circ}$, se tendrá en cuenta lo siguiente:

a) la semejanza gráfico fonética;

b) la semejanza conceptual;

c) si el signo incluye palabras genéricas y/o descriptivas, se realizará el análisis sobre la palabra o palabras de mayor fuerza distintiva.

\subsection{Signos Figurativos ${ }^{22}$}

Tratándose de signos figurativos, en adición a los criterios señalados en el Artículo 45 del D. Leg. $1075^{\circ}$, se tendrá en cuenta lo siguiente:

a) si las figuras son semejantes, si sucintan una impresión visual idéntica o parecida.

b) si las figuras son distintas, si evocan un mismo concepto.

20 Artículo $45^{\circ}$ del D. Leg. 1075 del 28 de Junio del 2008. “Decreto Legislativo que aprueba Disposiciones complementarias a la Decisión 486 de la Comisión de la Comunidad Andina que establece el Régimen Común sobre Propiedad Industrial.

21 Artículo $46^{\circ}$ del D. Leg. 1075.

${ }^{22}$ Artículo $47^{\circ}$ del D. Leg. 1075. 


\subsection{Signos Mixtos ${ }^{23}$}

Tratándose de signos mixtos, formados por una denominación y un elemento figurativo, en adición a los criterios señalados en el Artículo 45, 46 y 47 del Decreto Legislativo 1075, se tendrá en cuenta lo siguiente:

a) la denominación que acompaña al elemento figurativo.

b) la semejanza conceptual;

c) la mayor o menor relevancia del aspecto denominativo frente al elemento gráfico, con el objeto de identificar la dimensión característica del signo.

\subsection{Semejanza conceptual ${ }^{24}$}

Tratándose de signo denominativo y uno figurativo, se tendrá en consideración la semejanza conceptual. Tratándose de un signo denominativo y un mixto, se tendrá en cuenta los criterios señalados en los artículos 45 y 47 del Decreto Legislativo 1075. Tratándose de un signo figurativo y uno mixto, se tendrán en cuenta los criterios señalados en el Art. $47^{\circ}$ y $48^{\circ}$ del Decreto en comentario.

En los tres supuestos, serán igualmente de aplicación los criterios señalados en el Art. 45 del mismo cuerpo legal en comentario.

\section{Derechos conferidos por el registro de una marca}

El registro de una marca tendrá una duración de diez años contados a partir de la fecha de su concesión, y podrá renovarse por períodos sucesivos de diez años; ello va a depender de la voluntad del empresario de querer continuar con los derechos adquiridos por el registro de su marca. El empresario titular del registro de una marca; deberá solicitar la renovación del registro ante Dirección de signos distintivos, dentro de los seis meses anteriores a la expiración del registro.

Consideramos entre los derechos que confiere el registro, el más importante es el derecho al uso exclusivo de una marca. El empresario titular de la marca podrá renunciar en cualquier momento, total o parcialmente a sus derechos marcarios, la mis que surtirá efecto desde el momento de su inscripción. El registro de una marca confiere a su titular el derecho de impedir a cualquier tercero realizar, sin su consentimiento, los siguientes $\operatorname{actos}^{25}$ :

${ }^{23}$ Artículo $48^{\circ}$ del D. Leg. 1075.

24 Artículo $49^{\circ}$ del D. Leg. 1075.

25 Decisión $486^{\circ}$ "Régimen común sobre la Propiedad Industrial" 
a) aplicar o colocar la marca o un signo distintivo idéntico o semejante sobre productos para los cuales se ha registrado la marca; sobre productos vinculados a los servicios para los cuales ésta se ha registrado; o sobre los envases, envolturas, embalajes o acondicionamientos de tales productos;

b) suprimir o modificar la marca con fines comerciales, después de que se hubiese aplicado o colocado sobre los productos para los cuales se ha registrado la marca; sobre los productos vinculados a los servicios para los cuales ésta se ha registrado; o sobre los envases, envolturas, embalajes o acondicionamientos de tales productos;

c) fabricar etiquetas, envases, envolturas, embalajes u otros materiales que reproduzcan o contengan la marca, así como comercializar o detentar tales materiales;

d) usar en el comercio un signo idéntico o similar a la marca respecto de cualesquiera productos o servicios, cuando tal uso pudiese causar confusión o un riesgo de asociación con el titular del registro. Tratándose del uso de un signo idéntico para productos o servicios idénticos se presumirá que existe riesgo de confusión;

e) usar en el comercio un signo idéntico o similar a una marca notoriamente conocida respecto de cualesquiera productos o servicios, cuando ello pudiese causar al titular del registro un daño económico o comercial injusto por razón de una dilución de la fuerza distintiva o del valor comercial o publicitario de la marca, o por razón de un aprovechamiento injusto del prestigio de la marca o de su titular;

f) usar públicamente un signo idéntico o similar a una marca notoriamente conocida, aun para fines no comerciales, cuando ello pudiese causar una dilución de la fuerza distintiva o del valor comercial o publicitario de la marca, o un aprovechamiento injusto de su prestigio.

\section{Conclusiones}

El estudio del Derecho Marcario nace con la revolución industrial durante los siglos XVIII a XIX, con el vapor aplicado a la industria, cuando James Watt inventó la primera máquina a vapor con combustible de hulla en 1764 en Birmingham. En el Perú antiguo, no se tiene conocimiento exacto que hubiera existido marcas distintivas de productos o servicios; con el avance de la ciencia y la tecnología llegaba un poco tarde a nuestro país como el hierro, la electricidad, el barco, los ferrocarriles, los mismos que permitían el transporte de las mercaderías, con el engrandecimiento del comercio, recién llega al Perú las marcas de productos y servicios. 
Nuestras normas de propiedad industrial han sido muy pocas, a diferencia de otras materias del derecho; e inclusive nuestra bibliografía nacional también es escasa, el cual a mi parecer dificulta que nuestros estudiantes de derecho puedan profundizar sus estudios en el Derecho Marcario y puedan obtener una especialista en Derecho Marcario.

La marca cumple un rol primordial en la vida del empresario que pretenda crecer en el mercado nacional. Marcar su producto o servicios no solo es darle exclusividad en el uso de la marca, sino también adquiere la protección debida evitando que la competencia desleal pueda utilizarla de mala fe.

El Indecopi, como organismo autónomo, no solo tiene la función de vigilar la libre iniciativa privada y la libertad de empresa, sino que tiene una función más importante que es la de proteger los derechos otorgados a los elementos constitutivos de la propiedad industrial. La dirección de signos distintivo es la encargada de realizar el examen de confundibilidad marcaria, cuando existan dos signos que presentan ciertos elementos semejantes o similares en sus respectivas configuraciones a fin de evitar un posible error al público consumidor respecto a la identidad de los productos o servicios que los signos en conflicto identifican y, en algunos casos en cuanto al origen empresarial de los mismos.

El examen de confundibilidad marcaria se debe realizar cuando un tercero haya presentado un recurso de oposición a la solicitud del registro, pero ello nada impide que la Dirección de Signos Distintivos, muy a pesar que no se presenta ninguna oposición realice de oficio el examen de confundibilidad.

Para concluir, debemos precisar que la norma complementaria a la Decisión $486^{\circ}$ ha previsto los criterios que debe tomar en cuenta el Indecopi a fin de que los signos solicitados para su registro no logren causar confusión y error al consumidor; criterios que se debe tomar en cuenta cuando se presentan signos denominativos, signos mixtos, semejanza conceptual. 


\section{Bibliografía}

- BAYLOS, Hermenegildo, Tratado de Derecho Industrial. Ed. Civitas: Madrid, 1978.

- CHAVEZ PICASSO, Jorge. "El régimen común de Derecho Marcario y su interpretación por el Tribunal de Justicia de la Comunidad Andina", en: Revista de la Competencia y la Propiedad Intelectual $\mathrm{N}^{\circ} 7$.

- FERNANDEZ-NOVOA, Fernández. Tratado sobre Derecho de Marcas. Marcial Pons: Madrid, 2004.

- KRESAljA ROSSELlÓ, Baldo. La Propiedad Industrial. Evolución y Tratamiento Normativo en la Región Andina y el Perú. Palestra Editores: Lima, 2004.

- NUÑEZ DEL PRADO, Oscar Holguín. Tratado de Derecho de Propiedad Industrial. Marcas de Productos y de Servicios (Volumen Segundo). Lima, 1997.

- OTAMENDI, Jorge. Derecho de Marcas. Editorial Abeledo Perrot: Buenos Aires, 1995.

- URÍA, Rodrigo. Derecho Mercantil. Editorial Marcial Pons: Madrid, 1994.

\section{Normas de propiedad industrial}

- Desición 486 "Régimen Común sobre la Propiedad Industrial"

- Decreto Legislativo 1075 "Decreto Legislativo que Aprueban Disposiciones complementarias a la Decisión 486 de la Comisión de la Comunidad Andina que Establece el Régimen Común Sobre Propiedad Industrial”

- Decreto Legislativo 1033 "Decreto Legislativo que aprueba la Ley de Organización y Funciones del Instituto Nacional de Defensa de la Protección de la Propiedad Intelectual (Indecopi)" 